\title{
The Many Faces of Hegemony: Social Complexity and Political Strategies
}

\section{Williams, Alex. Political Hegemony and Social Complexity: Mechanisms of Power After Gramsci. Palgrave MacMillan, 2020, pp. 252.}

In recent decades, the concept of "complexity" has been one of the leitmotifs of social science used to open the conceptual baggage needed to understand the dynamics of "post-modernity," primarily the composition and structure of society, and the mutations of the technologies of government. Alex Williams, a British political scientist, is best known for the important work Inventing the Future: Postcapitalism and a World Without Work, co-written with Nick Srnicek, which posed the politically dense and central problem of the collective use of technologies to "accelerate" the overcoming of capitalism. His latest book, Political Hegemony and Social Complexity: Mechanism of Power After Gramsci, elaborates on some of the diagnoses set out in the previous one, especially those concerning neoliberalism as not merely an economic but a total social phenomenon, and those on the ambivalent, porous, and productive intertwining of politics and technology. The focus on hegemony allows Williams to connect the cultural utopia of accelerationism to antagonistic political practice by comparing the previously elaborated concept of "folk politics ${ }^{[1]}$ with the theme of organization. Among the many lines of interpretation that the political machine of hegemony possesses, one certainly refers to the renewal of left politics, that is, to the overcoming of the stasis between Party and Movement, between Ideology and Culture, between State and Opposition.

The book is composed of eleven chapters and can be read through three argumentative axes. The first axis is that which presents the notion of "complexity," straddling science, technology, and 
sociology. The second is the one that, starting from Gramsci, questions the notion of "hegemony" and follows its evolution in other discursive regimes. The last one binds the two terms in an analytical device, the "complex hegemony," to analyze the transformations which have emerged in the past forty years, especially Neoliberalism.

The second chapter of the book, following the introduction, deals with "complexity" in contemporary social sciences as an "objective," therefore not ideological, attempt to analyze and interpret social changes. In this sense, we should not be surprised by the theoretical openness to other discursive fields, such as cybernetics, physics, and thermodynamics, as evidenced in the genealogy traced by Williams, as well as in the authors he uses to support the historical reconstruction (such as Wiener, Prigogine, Stengers). Complexity, therefore, allows us to shed light on the social structure, but from a new and, in some ways, innovative perspective. In this way, the whole social structure can be presented as a network composed of numerous components and numerous links in a nonlinear form, in which other subsystems, or even competing systems, can emerge in a "strong" or "weak" way.

In the third chapter, Williams focuses on the "effective" dimension of social structures, that is, their condition of emergence and their actual validity. The morphogenetic process of the structure is articulated both on the space-time coordinates and on the relational subsystems it generates and reproduces within itself - the emergence of the structure is contiguous and simultaneous with the emergence of the actors operating within it. This allows us to theorize the multi-layering of structure and the multiplication of intra- and extra-systemic links, which does not undermine the heuristic and "centralizing" power of the system. The concept of "phase space," the central theme of the fourth chapter, allows to analyze the dynamics between the system and its parameters, and therefore to work on abstract models of prediction of possible interactions - between the minimumstable equilibrium and the maximum-chaos, the system exists both as a hierarchical structure and as a virtual multiplicity, as a network of relationships (De Landa) in constant dynamics. In this way, the different equilibrium states of the system are related to variations in subsystem relationships, properties of emerging systems, and relationships among actors: "Complex system analysis might enable us to discover which options likely lie ahead, but not which precise ones will occur. It is only 
through human agency, conceived as a key perturbatory force at times of phase transition, that these options are decided upon" (Williams 60).

Williams takes up Simondon's critique of hylomorphism, of the coactive hypostasis of social dynamics within structure, and analyzes theories of social self-organization. The liberalist catallaxis of Hayek and his disciples, and the anarchic thought of Kropotkin and Bookchin are the two opposite poles in which the author hinges a first problematization of structural complexity. In this sense, if the project of the liberal revolution used the concept of catallaxis as a picklock to disengage the action of private individuals from the control of the state, the thought of anarchist self-organization offers a means to rethink the political organization from a conflictual perspective.

The next two chapters focus on the theory of hegemony in Gramsci and its reinterpretation in the post-structuralist field. The first, chapter six, is devoted to the Sardinian revolutionary. Notoriously, he, by situating hegemony in an intermediate space between structure and superstructure of Marxian memory, assumes the whole of society into an element of observation and analysis. Moreover, it recognizes the fundamental importance of the media, effective agents of collective enunciation, as means of organization within the world of culture, thus within the social division of capitalist labor.

And it is precisely the interstitial dimension of Gramscian analytics that is the starting point of the post-structuralist theory of hegemony, that of Mouffe and Laclau, which is the theme of the seventh chapter. Their main merit was to dislocate the Gramscian device on a completely different ground, recognizing its heuristic and political scope for the realization of "radical democracy." The two authors model social structure on linguistic structure and describe hegemony as a system of articulations between different signifier chains within an empty central signifier, the people, who are the subjects of democratic politics. Hegemony, in this sense, is a pure linguistic practice, albeit a multifunctional one. The British scholar accepts the central theoretical argument of the two authors, the stratification of the social milieu, but criticizes the reduction of hegemony to a pure instance of circulation, missing the "last instance determination" with the core of the systemic structure.

Williams, after theoretically fine-tuning the two concepts, goes on to enucleate the different forms of "complex hegemony" in chapter eight. These are as follows: hegemony as an emergent property of the system, hegemony as a vector of self-organization, hegemony as a metastable equilibrium 
point, and hegemony as a form of generative entrenchment. To a specific model of system corresponds the exercise of one (or more) hegemonic power, which realize the specific ends of the system itself. Thus, materialistically, for every complex hegemonic structure, there are organizational politics of hegemony, as can be seen in chapter nine: ideological hegemony, economic hegemony, state hegemony, sociotechnical hegemony. The combination of these differentials can result in a precise politics of hegemony, aimed at the complexity of the issues: "The politics of complex hegemony, therefore, is 'experimental' in character, in the sense of having to proceed always at least partly without fully knowing the results of its actions ... Hegemonic strategy is emergent" (Williams 180-81).

Moreover, these different models find a place in the analysis of neoliberalism as a hegemonic historical cycle, to which chapter ten is devoted. The original matrix of neoliberal discourse, straddling theoretical elaboration and economic experimentation, has been grafted over time into the devices of enunciation and communication to become fully ideological common sense (as in the case of austerity), economic complexity (as in the case of the processes of financialization), and cultural production. For Williams, the liberal hegemonic machine is at once economic, cultural, and libidinal because it has occupied the void left by the failure of state policies, failed promises of intellectual emancipation, and social structures. The epistemological complex hegemony has been, in fact, transformed into a hegemony of complexity suitable for "mapping" the different abstractions of neoliberal capitalism (to use the happy expression of Fredric Jameson).

The concluding chapter of the book (11), in addition to summing up the issues discussed, metaphorically poses one of the most classic questions in antagonist political practice: What to do? Certainly, as Williams calmly states, alternative policy options to neoliberal hegemony have proven ineffective. Left populism, deliberative democracy, and assembly-based organizational models, although they have stimulated active participation, have failed either to produce common sense or to constitute themselves as counter-hegemonic poles. In this sense, the "return" to Gramscian revolutionary realism, in fact, permits to link social heterogeneity to an organizational political project. Williams himself combines Marxist readings of hegemony after Gramsci (as put forward by Althusser and Balibar) with studies on the organizational dynamics of networks, first of all Bruno Latour's "Actor Network Theory." 
In conclusion, Williams's book is a useful and important piece of contemporary political theory. The impressive research work allows the author to rethink, from a specific point of view, the relationship between political theory and complexity, that is, to broaden the horizon of hegemony to the most recent phenomena of informatization of the social.

In the Marxian terms that Williams uses in the final lines of the book, building hegemony requires a politics of abstraction, that is, a politics that holds within it the multiplicity of social phenomena and the long-term historical horizon. This additional political indication enhances the value of Williams's work and invites readers and scholars to develop practices of collective freedom and democracy that are appropriate to the challenges and pitfalls of the contemporary world.

\section{Works Cited}

Williams, Alex. Political Hegemony and Social Complexity: Mechanisms of Power After Gramsci. Palgrave MacMillan, 2020. 
[1] The concept of "folk politics" can be understood as the set of collective policies "from below," characterized by immediacy and the absence of strategic visions of medium to long term

\section{(c) (i) (9)}

Creative Commons Attribution-NonCommercial-NoDerivatives 4.0 International License 